\title{
Phosphate Adsorption Ability of Granular Gibbsite and Cerium Hydroxide
}

\author{
Fumihiko Ogata, Hisato Tominaga, Hitoshi Yabutani and Naohito Kawasaki * \\ Faculty of Pharmacy, Kinki University (3-4-1 Kowakae, Higashi-Osaka, Osaka 577-8502, JAPAN)
}

\begin{abstract}
In the present study, the phosphate adsorption abilities of granular materials, gibbsite (GB) and cerium hydroxide (CE), granulated with ethyl cellulose and ethanol, were investigated. For suitable granular conditions using GB or CE, the percentage of binder and amount of solvent were $10 \%$ and 3.25 $\mathrm{mL} / 5 \mathrm{~g}$ for GB and $7.5 \%$ and $2.50 \mathrm{~mL} / 5 \mathrm{~g}$ for CE. The amount of phosphate adsorbed by granular GB or CE was similar to that adsorbed by powdered GB or CE. The adsorption isotherms of phosphate were also similar for the granular and powdered materials. The results of a column experiment showed that when GB was used, the suitable concentration of sodium hydroxide as the desorption solution was $2 \mathrm{mmol} / \mathrm{L}$. In these experiments, the amount of phosphate adsorbed was $31.4 \mathrm{mg} / \mathrm{g}$, the amount of phosphate desorbed was 25.3 $\mathrm{mg} / \mathrm{g}$, and the recovery percentage was $80.5 \%$. In contrast, when $\mathrm{CE}$ was used, the suitable concentration of sodium hydroxide was $500 \mathrm{mmol} / \mathrm{L}$; the amount of phosphate adsorbed was $77.7 \mathrm{mg} / \mathrm{g}$, the amount of phosphate desorbed was $57.8 \mathrm{mg} / \mathrm{g}$, and the recovery percentage was $\mathbf{7 4 . 4 \%}$. Results also indicate that granular GB and CE could be used at least five times in a column without loss of absorption or desorption abilities. Moreover, granulation of GB and CE is possible using ethyl cellulose and ethanol.
\end{abstract}

Key words: phosphate, adsorption, gibbsite, cerium hydroxide

\section{INTRODUCTION}

Phosphate is widely known to cause eutrophication in lakes and enclosed sea areas, often resulting in the occurrence of red tides or blue-green algae blooms ${ }^{1)}$. Red tides and algae blooms can be induced even at low phosphate concentrations, and technologies that remove phosphates at low concentrations have been investigated. On the other hand, phosphate is considered a very important natural resource. For example, in the United States, phosphate is a strategic natural resource and its export is therefore regulated. Presently, Japan depends on the import of phosphate materials, and phosphate recovery techniques have been investigated to counter situations of high prices and unavailability. Some of these techniques involve red $\mathrm{mud}^{2-4)}$, a biological method ${ }^{5)}$, $\operatorname{slag}^{6)}$, adsorbents ${ }^{7,8)}$, iron oxide tailing $^{9)}$, anion binding on functionalized nanoporous sorbents $^{10)}$, coal fly ash ${ }^{11)}$, Mg-Mn-layered double hydroxides $^{12)}$, and a Fe-Mn binary oxide adsorbent ${ }^{13)}$. In addition, the recovery and reuse of phosphate materials has also been considered. A flow system with a column is also a very useful approach for extracting desired materials, because it is easy to change the sample solution to the recy- cling solution and recover the desired materials. To use adsorbents in a column, the diameter of the adsorbent must be large to some extent. More specifically, the adsorbent must be granulated. The adsorption of phosphate using granular red mud at a very high sintering temperature has been reported ${ }^{14)}$. Phosphate removal using a column ${ }^{15,16)}$ and long-term (approximately 70 weeks) experiments have also been reported ${ }^{17)}$.

We have previously reported that powdered aluminum compounds, aluminum oxyhydroxide (boehmite, BE), and aluminum hydroxide (gibbsite, GB) exhibit high phosphate adsorption abilities ${ }^{18-20)}$. In addition, powdered cerium hydroxide (CE) is also known to exhibit a high phosphate adsorption ability. However, the phosphate adsorption abilities of granular BE, GB, and CE have not yet been reported.

In the present study, granulation of GB and CE with ethyl cellulose and ethanol and the subsequent adsorption abilities of granular GB or CE in a column were evaluated.

\footnotetext{
*Correspondence to: Naohito Kawasaki, Faculty of Pharmacy, Kinki University, 3-4-1 Kowakae, Higashi-Osaka, Osaka 577-8502, JAPAN

E-mail: kawasaki@phar.kindai.ac.jp

Accepted September 2, 2010 (received for review May 28, 2010)

Journal of Oleo Science ISSN 1345-8957 print / ISSN 1347-3352 online

http://www.jstage.jst.go.jp/browse/jos/
} 


\section{F. Ogata, H. Tominaga, H. Yabutani and N. Kawasaki}

\section{EXPERIMENTAL PROCEDURES}

\subsection{Materials}

GB (GBH-42M) was purchased from Showa Denko (Tokyo, Japan). The chemical composition of GB is: adhesion moisture (0.23\%), $\mathrm{Al}(\mathrm{OH})_{3}(99.6 \%), \mathrm{Fe}_{2} \mathrm{O}_{3}(0.01 \%), \mathrm{SiO}_{2}$ $(0.01 \%), \mathrm{Na}_{2} \mathrm{O}(0.33 \%)$, and $\omega-\mathrm{Na}_{2} \mathrm{O}(0.05 \%)$. The average particle size, bulk density (light), bulk density (heavy), and moisture adsorption capacity were $1.1 \mu \mathrm{m}, 0.2 \mathrm{~g} / \mathrm{cm}^{3}, 0.5 \mathrm{~g} /$ $\mathrm{cm}^{3}$, and $0.90 \%$, respectively. Cerium hydroxide (CE) was purchased from Wako Pure Chemical Industries Co., Ltd. (Tokyo, Japan). CE included $\mathrm{CeO}_{2}$ at $80-87 \%$, and was soluble in acidic solutions, but not in alkaline solutions. The binder and solvent used for granulation were ethyl cellulose and ethanol, respectively. Granulated GB (GBs I-V) with particle sizes of 500-840 $\mu \mathrm{m}$, was obtained after adding $0.250-0.750 \mathrm{~g}$ of ethyl cellulose and $2.250-3.750 \mathrm{~mL}$ of ethanol to $4.250-4.750 \mathrm{~g}$ of calcined $\mathrm{GB}$ at $450^{\circ} \mathrm{C}$ and drying at $110^{\circ} \mathrm{C}$ for $24 \mathrm{~h}$. Granulated CE (CEs I-VI) with particle sizes of 500-840 $\mu \mathrm{m}$, was obtained after adding 0.250-1.000 g of ethyl cellulose and 2.00-2.50 mL of ethanol to $4.000-4.750 \mathrm{~g}$ of virgin $\mathrm{CE}$ and drying at $110^{\circ} \mathrm{C}$ for $3 \mathrm{~h}$ (Table 1). The ability of calcined $\mathrm{GB}$ at $450^{\circ} \mathrm{C}$ (powder, $\mathrm{P}-\mathrm{GB}$ ) or virgin $\mathrm{CE}$ (powder, P-CE) to adsorb phosphate has been reported to be higher than that for powdered GBs or $\mathrm{CEs}^{18)}$.

\subsection{Phosphate adsorption ability}

The phosphate adsorption ability of GBs I-V or CEs I-VI was measured as follows. GBs I-V $(0.1 \mathrm{~g})$ were added to 50 $\mathrm{mL}$ of phosphate solution $(107 \mathrm{mg} / \mathrm{L})$ and shaken at 100 rpm for $15 \mathrm{~h}$ at $25^{\circ} \mathrm{C}$. The phosphate concentration in the filtrate was subsequently measured using a DR/890 Colorimeter (Hach Co., Loveland, CO, USA). The amount of phosphate adsorbed was calculated as the difference between the initial concentration and equilibrium concentra- tion. The initial concentration of the phosphate solution was $1,085 \mathrm{mg} / \mathrm{L}$ for CEs I-VI (0.5 g); all other experimental procedures were identical.

\subsection{Adsorption isotherm}

After adding $0.2 \mathrm{~g}$ of P-GB and GBII to $20 \mathrm{~mL}$ of the phosphate solution (131-1110 mg/L) and shaking at 100 rpm for $15 \mathrm{~h}$ at $25^{\circ} \mathrm{C}$, the solution was filtrated through a $0.45 \mu \mathrm{m}$ membrane filter (ADVANTEC). The equilibrium concentration was measured using the DR/890. The amount of phosphate adsorbed was calculated as the difference between the initial and final concentrations. For virgin P-CE and CEIII, the initial concentration of the phosphate solution was $138-2020 \mathrm{mg} / \mathrm{L}$; all other experimental procedures were identical.

\subsection{Adsorption of phosphate in a column}

The amount of phosphate adsorbed in a column (diameter $\times$ height: $1.0 \mathrm{~cm} \times 10.0 \mathrm{~cm}$ ) was measured as follows (Fig. 1). GBII was first added at a level $3.0 \mathrm{~cm}$ above the base of the column. Approximate conditions for the column experiment were as follows: initial concentration of phosphate, 10 mg/L; space velocity (S.V.), 25.48 1/h; linear velocity (L.V.), $0.76 \mathrm{~m} / \mathrm{h}$; flow rate, $1 \mathrm{~mL} / \mathrm{min}$; and adsorption time, $24 \mathrm{~h}$. The amount of phosphate adsorbed was calculated as the difference between the initial concentration and the concentration released from the column. After adsorption for $24 \mathrm{~h}$, the desorption process was investigated. Sodium hydroxide $(2,10$, and $20 \mathrm{mmol} / \mathrm{L}$ ) was used as the desorption solution, and the desorption time was $3 \mathrm{~h}$. The adsorption and desorption experiments were repeated five times. For CEIII, all experimental procedures were identical except for flow time $(72 \mathrm{~h})$ and the concentration of sodium hydroxide as the desorption solution (100, 500 and $1,000 \mathrm{mmol} / \mathrm{L}$ ).

Table 1 Granular GB and CE preparations.

\begin{tabular}{cccccc}
\hline \multirow{2}{*}{ Sample } & Type & $\begin{array}{c}\text { Binder } \\
(\%)\end{array}$ & $\begin{array}{c}\text { GB or CE } \\
(\mathrm{g})\end{array}$ & $\begin{array}{c}\text { Ethyl cellulose } \\
(\mathrm{g})\end{array}$ & $\begin{array}{c}\text { Ethanol } \\
(\mathrm{mL})\end{array}$ \\
\hline \multirow{3}{*}{ GB } & I & 15.0 & 4.250 & 0.750 & 3.25 \\
& II & 10.0 & 4.500 & 0.500 & 3.25 \\
& III & 5.0 & 4.750 & 0.250 & 3.25 \\
& IV & 10.0 & 4.500 & 0.500 & 2.25 \\
& V & 10.0 & 4.500 & 0.500 & 3.75 \\
& I & 20.0 & 4.000 & 1.000 & 2.50 \\
& II & 10.0 & 4.500 & 0.500 & 2.50 \\
& III & 7.5 & 4.625 & 0.375 & 2.50 \\
& IV & 5.0 & 4.750 & 0.250 & 2.50 \\
& V & 10.0 & 4.500 & 0.500 & 2.00 \\
& VI & 7.5 & 4.625 & 0.375 & 2.00 \\
\hline
\end{tabular}




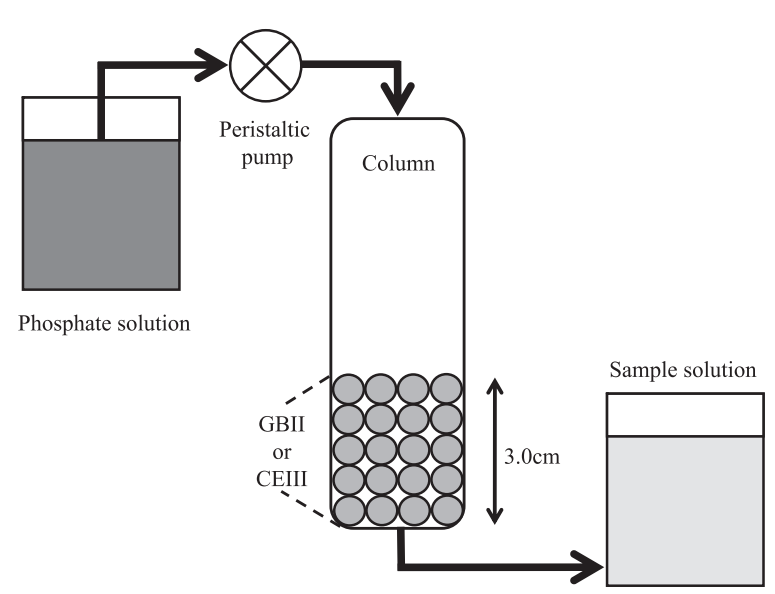

Fig. 1 Schematic of flow system with phosphate solution.

Column: diameter $1.0 \mathrm{~cm} \times$ height $10.0 \mathrm{~cm}$, Initial concentration of phosphate solution: 10 $\mathrm{mg} / \mathrm{L}$, Flow rate: $1.0 \mathrm{~mL} / \mathrm{min}$, Adsorption time: 24 h (72 h), Desorption time: 3 h, S.V.: 25.48 1/h, L. V.: $0.76 \mathrm{~m} / \mathrm{h}$.

\section{RESULTS AND DISCUSSION}

3.1 Phosphate adsorption ability of GBs I-V and CEs I-VI

The amount of phosphate adsorbed by GBs I-V and CEs I-VI is shown in Fig. 2. As shown in this figure, the amount of phosphate adsorbed by GB decreases with increasing binder concentration, suggesting that the phosphate adsorption site on the GB surface is masked by the binder. GBIII and GBIV collapsed after adsorption. These results indicate that the suitable granular conditions for GB include a binder percentage of $10 \%$ and $3.25 \mathrm{~mL} / 5 \mathrm{~g}$ of solvent. For CEs I-VI, the amount of phosphate adsorbed by CE also decreases with increasing binder, similar to GBs I-V. However, the amount of phosphate adsorbed by CE does not change when different amounts of ethanol are used during granulation. Moreover, CEV collapsed after adsorption. These results indicate that the suitable granular condition for CE is either the CEIII or CEIV condition. Taking into consideration the cost of granulation, the amount of ethanol used should be minimized. Thus, the suitable granular conditions for $\mathrm{CE}$ include a binder percentage of $7.5 \%$ and a solvent amount of $2.5 \mathrm{~mL} / 5 \mathrm{~g}$.

\subsection{Adsorption isotherms}

Previous reports have shown that the highest amount of phosphate adsorbed was obtained using calcined GB at $450^{\circ} \mathrm{C}$ (P-GB) and virgin $\mathrm{CE}(\mathrm{P}-\mathrm{CE})^{18)}$. The phosphate adsorption isotherms of GB and CE are shown in Fig. 3. At an equilibrium concentration greater than $300 \mathrm{mg} / \mathrm{L}$, the amount of phosphate adsorbed by P-GB was larger than that adsorbed by GBII. At an equilibrium concentration less than $300 \mathrm{mg} / \mathrm{L}$, the amount of phosphate adsorbed by

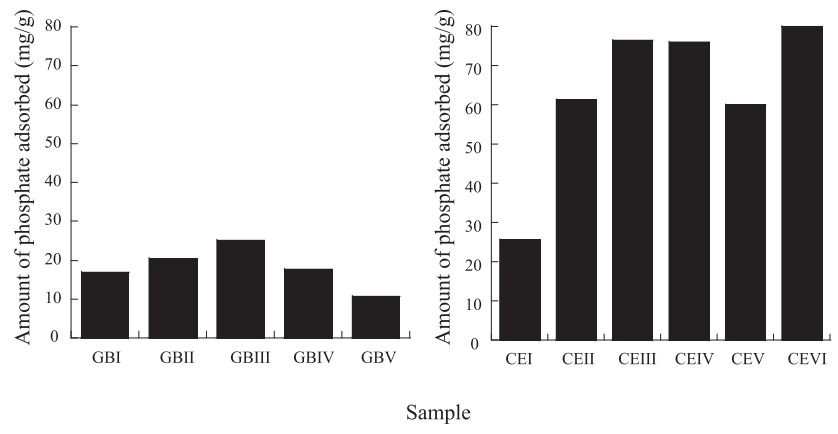

Fig. 2 Amount of phosphate adsorbed by granular GBs or CEs.
GB

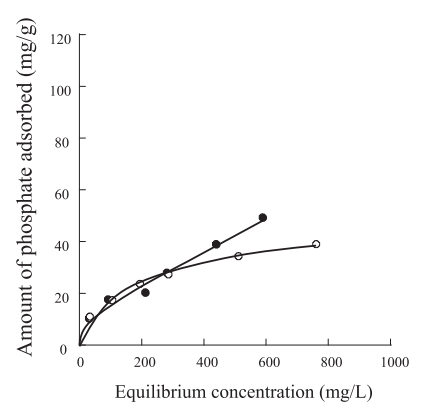

CE

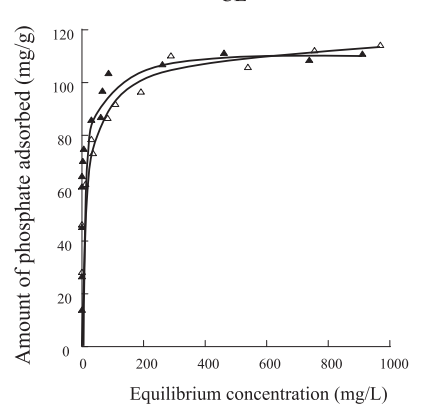

Fig. 3 GB and CE phosphate adsorption isotherms. : : P-GB, $\bigcirc$ : GBII, $\Delta$ : P-CE, $\triangle$ : CEIII.

P-GB and GBII were nearly identical. The phosphate concentration in an aqueous environment is very low, and it was shown that GBII was used in an aqueous environment. In contrast, the amount of phosphate adsorbed was nearly identical between P-CE and CEIII at all equilibrium concentrations. These results indicate that granular GB or CE with ethyl cellulose and ethanol could be used without decreasing their phosphate adsorption abilities. Phosphate adsorption isotherms are reported to approximate the Freundlich or Langmuir equation. Alternatively, adsorption data of various compounds onto adsorbents in the liquid phase are generally in accordance with the Freundlich equation(1). Therefore, adsorption ability is evaluated by its constants, $K$ and $1 / n$,

$$
V=K C^{(1 / n)}
$$

where $V$ is the amount adsorbed $(\mathrm{mg} / \mathrm{g}), C$ is the equilibrium concentration (mg/L), and $n$ and $K$ are adsorption constants. Constant $1 / n$, the slope of the Freundlich linear equation, numerically represents the affinity of the adsorbent for the adsorbate and constant $K$, an ordinate intercept, numerically represents the relationship of the adsorbent-adsorbate affinity to which the volume of adsorbate is added $^{21)}$. When constant $1 / n$ is in the range of 0.1-0.5, the adsorbate is considered to be easily adsorbed. On the other 
Table 2 Langmuir and Freundlich isotherm constants for phosphate adsorption.

\begin{tabular}{ccccccc}
\hline \multirow{2}{*}{ Adsorbent } & \multicolumn{3}{c}{ Langmuir model } & \multicolumn{3}{c}{ Freundlich model } \\
\cline { 2 - 7 } & $a(\mathrm{mg} / \mathrm{g})$ & $k$ & $r$ & $1 / n$ & $K$ & $r$ \\
\hline P-GB & 37.7 & 0.01 & 0.956 & 0.50 & 1.74 & 0.974 \\
GBII & 36.0 & 0.01 & 0.980 & 0.42 & 2.47 & 0.998 \\
P-CE & 110.9 & 1.56 & 0.979 & 0.15 & 47.17 & 0.843 \\
CEIII & 91.4 & 3.57 & 0.937 & 0.14 & 46.33 & 0.968 \\
\hline
\end{tabular}

hand, if $1 / n>2$, the adsorption is considered to be difficult $^{22)}$. The data shown in Fig. 3 were applied to the Freundlich equation, and constants $K$ and $1 / n$ were calculated (Table 2). As a result, the Freundlich plot is a linear curve with a correlation coefficient of 0.843-0.998, suggesting accordance with the Freundlich equation. Therefore, the mechanism by which phosphate is adsorbed onto GB or CE is considered to be a monomolecular adsorption to a heterogeneous surface. Moreover, adsorption data of various compounds onto adsorbents in the liquid phase also are generally in accordance with the Langmuir equation $(2)^{23)}$. Therefore, adsorption ability is evaluated by its constants, $a$ and $k$,

$$
V=a k C /(1+k C)
$$

where $V$ is amount adsorbed (mg/g), $C$ is equilibrium concentration $(\mathrm{mg} / \mathrm{L})$, and constants $k$ and $a$ are the adsorption equilibrium constant and the saturated amount adsorbed, respectively. The data shown in Fig. 3 were applied to the Langmuir equation, and $k$ and $a$ were calculated (Table 2). As a result, the Langmuir plot shows a linear curve with a correlation coefficient of 0.937-0.980. The constant $a$ of CE is larger than that of GB; that is, the saturated amount of phosphate adsorbed onto $\mathrm{CE}$ would be larger. The correlation coefficient of the Freundlich equation for phosphate adsorption onto GB or CE is the same as the correlation coefficient of the Langmuir equation for them. Since the Freundlich and Langmuir equations are based on monolayer adsorption theory, the adsorption behavior of phosphate onto GB or CE might be monolayer.

\subsection{Breakthrough curve}

The relationship between released concentrations of phosphate and elapsed time in the column with GBII is shown in Fig. 4, and the recovery percentages of phosphate in the column with GBII are listed in Table 3. The amount of phosphate adsorbed, amount of phosphate desorbed, and recovery percentage using 2,10 , and $20 \mathrm{mmol} /$ $\mathrm{L}$ sodium hydroxide as the desorption solution were 31.4 $\mathrm{mg} / \mathrm{g}, 25.3 \mathrm{mg} / \mathrm{g}$, and $80.5 \% ; 30.2 \mathrm{mg} / \mathrm{g}, 26.6 \mathrm{mg} / \mathrm{g}$, and $88.0 \%$; and $30.9 \mathrm{mg} / \mathrm{g}, 27.8 \mathrm{mg} / \mathrm{g}$, and $90.2 \%$, respectively. The recovery percentage of phosphate increases with increased concentrations of sodium hydroxide, suggesting that ion exchange occurs between phosphate and sodium

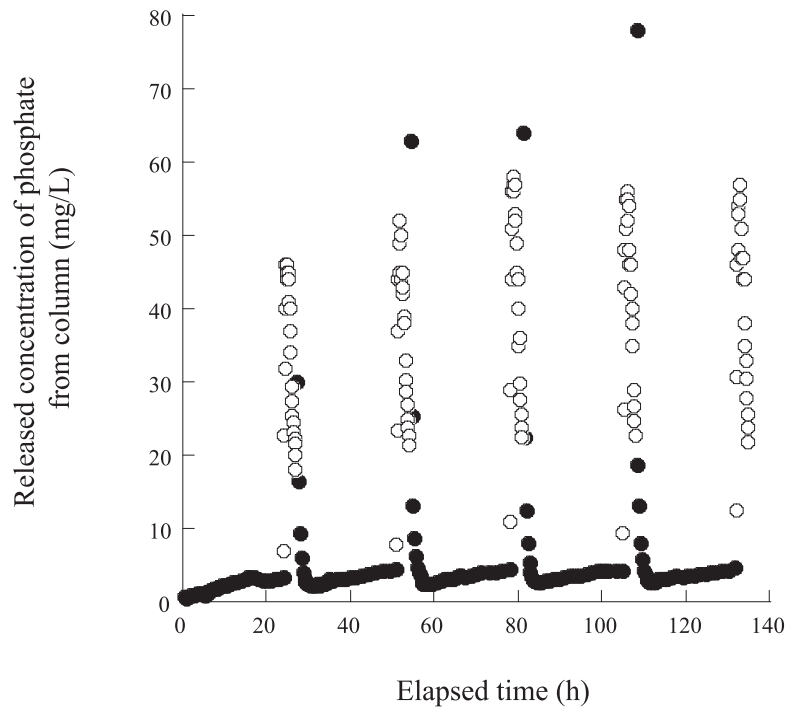

Fig. 4 Concentration of phosphate released from a column over time using GBII and $2 \mathrm{mmol} / \mathrm{L}$ sodium hydroxide.

$$
\text { : Adsorption, } \bigcirc \text { : Desorption. }
$$

hydroxide and the hydroxyl group is regenerated onto the adsorbent surface. Moreover, the lower concentration of sodium hydroxide could be used for the desorption solution. The first phosphate recovery percentage was 51-71\%, and subsequent recovery percentages were identical, suggesting that $2 \mathrm{mmol} / \mathrm{L}$ sodium hydroxide could be used for desorption of phosphate. In cases where the recovery percentage was greater than $100 \%$, the released phosphate included previously adsorbed phosphate. When $2 \mathrm{mmol} / \mathrm{L}$ sodium hydroxide was used, the released phosphate concentration was approximately $10 \%$ of the initial concentration immediately after adsorption and $30 \%$ of the initial concentration $24 \mathrm{~h}$ after adsorption. After five adsorption and desorption steps, the phosphate adsorption and desorption ability was unchanged, suggesting that GBII could be used as an adsorbent for phosphate removal.

The relationship between the released concentration of phosphate and elapsed time in the column with CEIII is shown in Fig. 5, and the recovery percentages of phosphate in the column containing CEIII are listed in Table 4. The amount of phosphate adsorbed, amount of phosphate desorbed, and recovery percentage using 100, 500, and 
Table 3 Recovery percentages of phosphate in a column with GBII.

\begin{tabular}{|c|c|c|c|c|c|c|c|c|c|c|c|c|c|c|c|}
\hline Times & & 1 & & & 2 & & & 3 & & & 4 & & & 5 & \\
\hline $\begin{array}{c}\mathrm{NaOH} \\
(\mathrm{mmol} / \mathrm{L})\end{array}$ & $\begin{array}{c}\mathrm{Ad} \\
(\mathrm{mg} / \mathrm{g})\end{array}$ & $\begin{array}{c}\mathrm{De} \\
(\mathrm{mg} / \mathrm{g})\end{array}$ & $\begin{array}{l}\mathrm{Re} \\
(\%)\end{array}$ & $\begin{array}{c}\mathrm{Ad} \\
(\mathrm{mg} / \mathrm{g})\end{array}$ & $\begin{array}{c}\mathrm{De} \\
(\mathrm{mg} / \mathrm{g})\end{array}$ & $\begin{array}{l}\mathrm{Re} \\
(\%)\end{array}$ & $\begin{array}{c}\mathrm{Ad} \\
(\mathrm{mg} / \mathrm{g})\end{array}$ & $\begin{array}{c}\mathrm{De} \\
(\mathrm{mg} / \mathrm{g})\end{array}$ & $\begin{array}{l}\mathrm{Re} \\
(\%)\end{array}$ & $\begin{array}{c}\mathrm{Ad} \\
(\mathrm{mg} / \mathrm{g})\end{array}$ & $\begin{array}{c}\mathrm{De} \\
(\mathrm{mg} / \mathrm{g})\end{array}$ & $\begin{array}{l}\mathrm{Re} \\
(\%)\end{array}$ & $\begin{array}{c}\mathrm{Ad} \\
(\mathrm{mg} / \mathrm{g})\end{array}$ & $\begin{array}{c}\mathrm{De} \\
(\mathrm{mg} / \mathrm{g})\end{array}$ & $\begin{array}{l}\mathrm{Re} \\
(\%)\end{array}$ \\
\hline 2 & 8.29 & 4.26 & 51 & 6.58 & 4.68 & 71 & 5.71 & 5.49 & 96 & 5.48 & 5.48 & 100 & 5.37 & 5.40 & 101 \\
\hline 10 & 7.39 & 5.22 & 71 & 6.01 & 4.59 & 76 & 5.60 & 5.70 & 102 & 5.69 & 5.35 & 94 & 5.52 & 5.72 & 104 \\
\hline 20 & 7.14 & 4.77 & 67 & 6.86 & 5.42 & 79 & 5.85 & 6.23 & 106 & 5.54 & 5.61 & 101 & 5.48 & 5.80 & 106 \\
\hline
\end{tabular}

Ad: Adsorption, De: Desorption, Re: Recovery percentage

Table 4 Recovery percentages of phosphate in a column with CEIII.

\begin{tabular}{|c|c|c|c|c|c|c|c|c|c|c|c|c|c|c|c|}
\hline Times & & 1 & & & 2 & & & 3 & & & 4 & & & 5 & \\
\hline $\begin{array}{c}\mathrm{NaOH} \\
(\mathrm{mmol} / \mathrm{L})\end{array}$ & $\begin{array}{c}\mathrm{Ad} \\
(\mathrm{mg} / \mathrm{g})\end{array}$ & $\begin{array}{c}\text { De } \\
(\mathrm{mg} / \mathrm{g})\end{array}$ & $\begin{array}{l}\mathrm{Re} \\
(\%)\end{array}$ & $\begin{array}{c}\mathrm{Ad} \\
(\mathrm{mg} / \mathrm{g})\end{array}$ & $\begin{array}{c}\mathrm{De} \\
(\mathrm{mg} / \mathrm{g})\end{array}$ & $\begin{array}{l}\mathrm{Re} \\
(\%)\end{array}$ & $\begin{array}{c}\mathrm{Ad} \\
(\mathrm{mg} / \mathrm{g})\end{array}$ & $\begin{array}{c}\mathrm{De} \\
(\mathrm{mg} / \mathrm{g})\end{array}$ & $\begin{array}{l}\mathrm{Re} \\
(\%)\end{array}$ & $\begin{array}{c}\mathrm{Ad} \\
(\mathrm{mg} / \mathrm{g})\end{array}$ & $\begin{array}{c}\mathrm{De} \\
(\mathrm{mg} / \mathrm{g})\end{array}$ & $\begin{array}{l}\mathrm{Re} \\
(\%)\end{array}$ & $\begin{array}{c}\mathrm{Ad} \\
(\mathrm{mg} / \mathrm{g})\end{array}$ & $\begin{array}{c}\mathrm{De} \\
(\mathrm{mg} / \mathrm{g})\end{array}$ & $\begin{array}{l}\mathrm{Re} \\
(\%)\end{array}$ \\
\hline 100 & 20.80 & 3.43 & 17 & 14.50 & 3.59 & 25 & 14.20 & 6.50 & 46 & 13.20 & 7.25 & 55 & 12.30 & 8.65 & 70 \\
\hline 500 & 20.10 & 9.70 & 48 & 14.70 & 9.34 & 64 & 15.40 & 11.30 & 74 & 13.90 & 13.30 & 96 & 13.60 & 14.20 & 104 \\
\hline 1000 & 20.10 & 11.00 & 55 & 15.70 & 12.30 & 78 & 15.60 & 14.70 & 94 & 14.90 & 15.40 & 103 & 15.50 & 15.50 & 100 \\
\hline
\end{tabular}

Ad: Adsorption, De: Desorption, Re: Recovery percentage

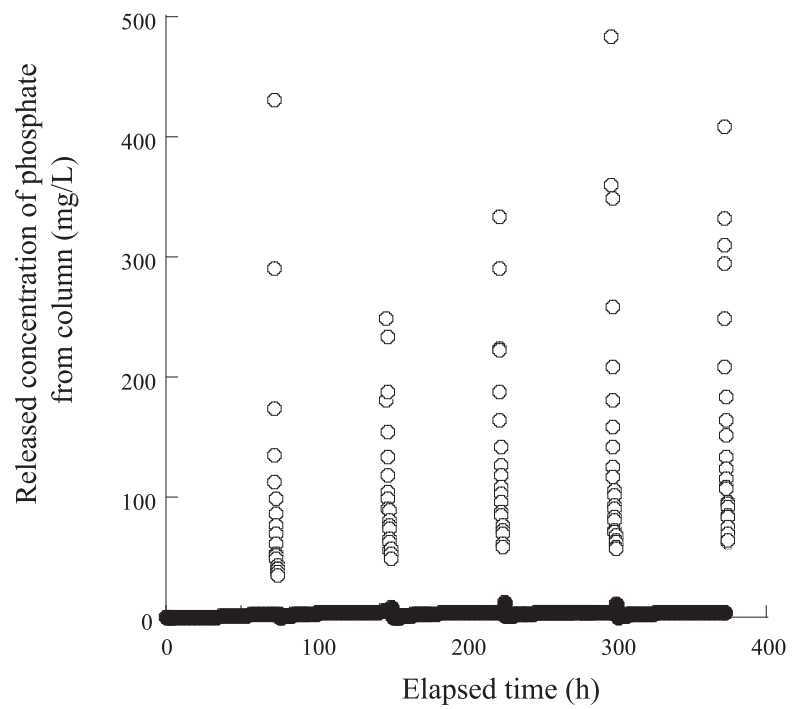

Fig. 5 Concentration of phosphate released from a column over time using CEIII and $500 \mathrm{mmol} / \mathrm{L}$ sodium hydroxide.

\section{: Adsorption, $\bigcirc$ : Desorption}

$1,000 \mathrm{mmol} / \mathrm{L}$ sodium hydroxide as the desorption solution were $75.0 \mathrm{mg} / \mathrm{g}, 29.4 \mathrm{mg} / \mathrm{g}$, and $39.2 \% ; 77.7 \mathrm{mg} / \mathrm{g}, 57.8 \mathrm{mg} /$ $\mathrm{g}$, and $74.4 \%$; and $81.8 \mathrm{mg} / \mathrm{g}, 68.9 \mathrm{mg} / \mathrm{g}$, and $84.2 \%$, respectively. The recovery percentage of phosphate increases with increasing concentration of sodium hydroxide similar to GBII. Compared to GBII, the amount of phosphate adsorbed by CEIII was two or three times greater, and a similar result was observed in the adsorption isotherms. In an aqueous environment, a lower concentration of sodium hydroxide could be used as the desorption solution. However, at the lower concentration of sodium hydroxide (100 $\mathrm{mmol} / \mathrm{L}$ ), the desorption percentage of phosphate was very low. Sodium hydroxide at a concentration of $500 \mathrm{mmol} / \mathrm{L}$ was more suitable for the desorption of phosphate. In cases where the recovery percentage was greater than $100 \%$, the released phosphate included previously adsorbed phosphate as well as that absorbed by GBII. When $500 \mathrm{mmol} / \mathrm{L}$ sodium hydroxide was used, the released concentration of phosphate was $0 \%$ of the initial concentration immediately after adsorption and approximately $30 \%$ of the initial concentration $24 \mathrm{~h}$ after adsorption. After five adsorption and desorption steps, the phosphate adsorption and desorption ability was unchanged. Thus, GBII and CEIII could be used for phosphate removal. Desorption of phosphate using GBII and CEIII was suitable at sodium hydroxide concentrations of $2 \mathrm{mmol} / \mathrm{L}$ and $500 \mathrm{mmol} / \mathrm{L}$, respectively, suggesting that GBII and CEIII can be used in an aqueous environment.

\section{CONCLUSION}

The phosphate adsorption abilities of granular GB or CE, generated using ethyl cellulose and ethanol for granulation, were investigated. The suitable granular conditions for GB include a binder percentage of $10 \%$ and an ethanol amount of $3.25 \mathrm{~mL} / 5 \mathrm{~g}$. Moreover, the suitable granular conditions for CE have a binder percentage of $7.5 \%$ and an ethanol amount of $2.50 \mathrm{~mL} / 5 \mathrm{~g}$. Compared to phosphate adsorption ability of P-GB or P-CE, the amount of phosphate adsorbed using GBII or CEIII were nearly identical. Granular GB and CE could thus be generated without decreasing their phosphate adsorption abilities.

In a column experiment using GB, the suitable sodium hydroxide concentration, amount of phosphate adsorbed, amount of phosphate desorbed, and recovery percentage were $2 \mathrm{mmol} / \mathrm{L}, 31.4 \mathrm{mg} / \mathrm{g}, 25.3 \mathrm{mg} / \mathrm{g}$, and $80.5 \%$, respec- 


\section{F. Ogata, H. Tominaga, H. Yabutani and N. Kawasaki}

tively. On the other hand, using CE, the suitable sodium hydroxide concentration, amount of phosphate adsorbed, amount of phosphate desorbed, and recovery percentage were $500 \mathrm{mmol} / \mathrm{L}, 77.7 \mathrm{mg} / \mathrm{g}, 57.8 \mathrm{mg} / \mathrm{g}$, and $74.4 \%$, respectively. Results further indicate that GBII and CEIII, successfully granulated using ethyl cellulose and ethanol, could be used at least five times in an aqueous environment without loss of adsorption or desorption abilities.

\section{ACKNOWLEDGEMENTS}

This work was financially supported by “Antiaging Center Project" for Private Universities from the Ministry of Education, Culture, Sports, Science and Technology, 2008-2012.

\section{References}

1) Chitrakar, R.; Tezuka, S.; Sonoda, A.; Sakane, K.; Ooi, K.; Hirotsu, T. Phosphate adsorption on synthetic goethite and akaganeite. J. Colloid Interface Sci. 298, 602-608(2006).

2) Zhao, Y.; Wang, J.; Luan, Z.; Peng, X.; Liang, Z.; Shi, L. Removal of phosphate from aqueous solution by red mud using a factorial design. J. Hazard. Mater. 165, 1193-1199(2009)

3) Wang, S. B.; Ang, H. M.; Tade, M. O. Novel applications of red mud as coagulant, adsorbent and catalyst for environmentally benign processes. Chemosphere. 72 , 1621-1635 (2008)

4) Huang, W.; Wang, S.; Zhu, Z.; Li, L.; Yao, X.; Rudolph, V.; Haghseresht, F. Phosphate removal from wastewater using red mud. J. Hazard. Mater. 158, 35-42 (2008).

5) Li, Y.; Liu, Z.; Peng, X.; Zhu, C.; Chen, Z., Zhang, J.; Fan, J.; Jiaz, Z. Phosphate removal from aqueous solutions using raw and activated red mud and fly ash. $J$. Hazard. Mater. B. 137, 374-383(2006).

6) Oguz, E. Thermodynamic and kinetics investigations of $\mathrm{PO}_{4}{ }^{3-}$ adsorption on blast furnace slag. J. Colloid Interface Sci. 281, 62-67 (2005).

7) Genz, A.; Kornmuller, A.; Kekel, M. Advanced phosphorus removal from membrane filtrates by adsorption on activated aluminum oxide and granulated ferric hydroxide. Water Res. 38, 3523- 3530 (2004).

8) Wu, R. S. S.; Lam, K. H.; Lee, J. M. N.; Lau, T. C. Removal of phosphate from water by a highly selective La (III)-chelex resin. Chemosphere. 69, 289-294 (2007).

9) Zeng, L.; Li, X. M.; Liu, J. D. Adsorptive removal of phosphate from aqueous solutions using iron oxide tailings. Water Res. 38, 1318-1326 (2004).
10) Chouyyok, W.; Wiacek, R. J.; Pattamakomsan, K.; Sangvanich, T.; Grudzien, R. M.; Fryxell, G. L. Phosphate removal by anion binding on functionalized nanoporous sorbents. Environ. Sci. Technol. 44, 3073-3078 (2010).

11) Pengthamkeerati, P.; Satapanajaru, T.; Chularuengoaksorn, P. Chemical modification of coal fly ash the removal of phosphate from aqueous solution. Fuel 87, 2469-2476 (2008).

12) Chitrakar, R.; Tezuka, S.; Sonoda, S.; Sakane, K.; Ooi, K.; Hirotsu, T. Adsorption of phosphate from seawater on calcined MgMn-layered double hydroxide. J. Colloid Interface Sci. 290, 45-51 (2005).

13) Zhang, G.; Liu, H.; Qu, J. Removal of phosphate from water by a Fe-Mn binary oxide adsorbent. J. Colloid Interface Sci. 335, 168-174(2009).

14) Yue, Q.; Zhao, Y.; Li, Q.; Li, W.; Gao, B.; Han, S.; Qi, Y.; $\mathrm{Yu}, \mathrm{H}$. Research on the characteristics of red mud granular adsorbents (RMGA) for phosphate removal. $J$. Hazard. Mater. 176, 741-748 (2010).

15) Xiaoping, Z.; Jyo, A. Column-mode phosphate removal by a novel highly selective adsorbent. Water Res. 39, 2301-2308(2005).

16) Xing Xu, B. G.; Wenyi Wang, Q. Y.; Yu Wang, S. N. Adsorption of phosphate from aqueous solutions onto modified wheat residue: Characteristics, kinetic and column studies. Colloids \& Surfaces B: Biointerfaces. 70, 46-52 (2009).

17) Agnieszka, R.; Gunno, R. Long-term phosphate removal by the calcium-silicate material polonite in wastewater filtration systems. Chemosphere. 79, 659-664 (2010).

18) Kawasaki, N.; Ogata, F.; Takahashi, K.; Kabayama, M.; Kakehi, K.; Tanada, S. Relationship between anion adsorption and physicochemical properties of aluminum oxide. J. Health Sci. 54, 324-329 (2008).

19) Kabayama, M.; Sakiyama, T.; Kawasaki, N.; Nakamura, T.; Araki, M.; Tanada, S. Characteristics of Phosphate ion adsorption-desorption onto aluminum oxide hydroxide. J. Chem. Engineer. Jpn. 36, 499-505 (2003).

20) Kabayama, M.; Kawasaki, N.; Nakamura, T.; Tanada, S. Adsorption/desorption characteristics of phosphate ion onto calcined boehmite surface. e-J. Surf. Sci. Nanotech. 3, 63-69 (2005)

21) Kondo, S.; Ishikawa, T.; Abe, I. Kyuuchaku no kagaku. Maruzen. Tokyo. p.104(1991).

22) Abe, I.; Hayashi, K.; Kitagawa, M. Studies on the adsorption of surfactants on activated carbons. I. Adsorption of nonionic surfactants. J. Jpn. Oil Chem. Soc. 25, 145-150 (1976).

23) Langmuir, I. The adsorption of gases on plane surfaces of glass, mica and platinum. J. Am. Chem. Soc. 40, 1361-1402 (1918). 